\title{
Physicochemical Studies of Calleandria Portoricensis Spp
}

\author{
Bello Hassan Onimisi \\ Olabisi Onabanjo University, Faculty of Pharmacy, Department of Medicinal Chemistry/Pharmaceutical \\ Chemistry, Nigeria \\ *Corresponding Author: Bello Hassan Onimisi, Olabisi Onabanjo University, Faculty of Pharmacy, \\ Department of Medicinal Chemistry/Pharmaceutical Chemistry, Nigeria
}

\begin{abstract}
Calleandria portoricensis spp is a plant that has been used in curing different ailments in south western part of nigeria. To further enhance the use of the plant and to legitimatize it before experts the physicochemical studies of this drug was carried out. The parameters applied for the present study are ash value, moisture content, PH value, TLC, fluorescent analysis and quantitative physicochemical studies.
\end{abstract}

Keywords: TLC, ash values and calleandria portoricensis spp

\section{INTRODUCTION}

Herbal medicine has existed over the years for many centuries. They have been used for medication from time immemorial. However, little attention has been given to its use, efficacies and its constituents by scientists. In the process of collection, storage and production of the medicine, it usually deteriorates due to poor handling and little knowledge of its indices of efficacy hence there is need to standardize the herbal product before sales and use. calleandria portoricensis spp is a herbal drug used as antibacterial and antifungal among its uses in Nigeria. The parameters applied in the present study makes valuable test to check the quality of drug.

\section{Materials ANd Methods}

Calleandria portoricensis spp was procured from a market in Sagamu in south west Nigeria and was confirmed in the Department of botany in university of lagos. it was air dried ,powdered in an electric grinder.

\section{Physicochemical Studies}

The usual methods were employed for the determination of extractive values and ash values. Moisture contents was determine by the method of Jenkin et al. The PH and TLC were carried out according to British pharmacopoeia while the phytochemical screening was carried out by Bhattacharjee and Das. flourescence analysis of the powdered drug was conducted by the method of chase and pratty.

\section{RESULTS AND DISCUSSION}

The result of the experiments carried out on the dried roots of calleandria portoricensis spp are:

PH:

Moisture contents: $11 \%$

TLC Analysis of Calleandria Portoricensis Spp

\begin{tabular}{|l|c|c|c|c|c|}
\hline Extract of drug & $\begin{array}{c}\text { Solvent } \\
\text { system }\end{array}$ & Spray/treatment & No. of spots & $\mathrm{R}_{\mathrm{f}}$ value & Colour of spots \\
\hline Hexane & $\begin{array}{c}\text { Hexane ethyl } \\
\text { ether(8:3) }\end{array}$ & $\begin{array}{c}40 \% \text { perchloric acid } \\
\text { heated at } 105 \%\end{array}$ & three & $\begin{array}{c}0.61,0.71, \\
0.70\end{array}$ & All black \\
\hline Pet ether & $\begin{array}{c}\text { Pet ether } \\
\text { acetone }(1: 9)\end{array}$ & $\begin{array}{c}10 \% \text { venalin,10\% } \\
\mathrm{H}_{2} \mathrm{SO}_{4}\end{array}$ & two & $0.68,0.67$ & Pink and black \\
\hline Acetone & Acetone & $\begin{array}{c}10 \% \text { venalin,10\% } \\
\mathrm{H}_{2} \mathrm{SO}_{4}\end{array}$ & One & 0.71 & All black \\
\hline
\end{tabular}

The TLC analysis shows colour of spots, the $\mathrm{R}_{\mathrm{f}}$ values and number of spots from three different extract of the root of calleandria portoricensis spp. The hexane extract in hexane ethyl ether solvent system gives three spots in the TLC analysis with $R_{f}$ values $0.61,0.71,0.70$. on the other hand, the pet ether extract in pet ether acetone solvent system gives two spots whose $\mathrm{R}_{\mathrm{f}}$ values are 0.68 and 0.67 .the last extract, acetone extract in acetone solvent system gives just one spot with Rf value 0.71 . This might also be the compound that appears in hexane ethyl ether extract. 

Fluorecence Analysis of Calleandria Portoricensis Spp

\begin{tabular}{|l|l|l|}
\hline s.no & Treatment c & Colour of powder under ultra violet light \\
\hline 1 & Powder as such & Green colour \\
\hline 2 & treated with NaOH in methanol & Light green \\
\hline 3 & Mounted with nitrocellulose in ehtylacetate & Dirty green \\
\hline 4 & Treated with NaOH mounted in nitrocellulose & Light green \\
\hline
\end{tabular}

The fluorescence analysis results above show appears as dirty green in ultra violet light. that the powder as such in ultra violet light appears as green. When such powder is treated in sodium hydroxide and in methanol it appears as light green. However, when the powder is mounted with nitrocellulose in ethylacetate it finally, after treating the powder with sodium hydroxide and mounted in nitrocellulose and viewed under ultra violet light. it appears as light green.

Extractive Value of Powdered Roots of Calleandria Portoricensis Spp

\begin{tabular}{|l|l|l|}
\hline S/No & Organic solvents & Mean percentage of extract \\
\hline 1 & Hexane & 0.1094 \\
\hline 2 & Ethylacetate & 0.0465 \\
\hline 3 & Acetone & 0.1817 \\
\hline 4 & Methanol & 0.0299 \\
\hline
\end{tabular}

The extractive value were carried out on the powered dried root using hexane, ethylacetate, acetone and methanol. the mean percentage of extracts are : 0.1094 in hexane ,0.0465 in ehtylecetate, 0.1817 in acetone and 0.0299 in methanol.

\section{CONCLUSION}

The various results above of the dried root powder of calleandria portoricensis spp in comparison with other crude drugs has shown that the powdered root would be a good source of pharmaceutical drugs aside been a good crude drugs. This is not a surprise as it is used in many local herbal homes for various medicinal uses.

\section{REFERENCES}

[1] Jenkins glenn L. Christian johns. E ,nager.P and George .P qualitative pharmaceutical chemistry, 1957, pp.34-44,243-44,247.257

[2] Bhattacharjee AK and Das AK ,phytochemical screening of some indian plants .quant.j crude drugs 1969,9,1408-1412

[3] Chase CR and pratty .R fluorescence of powdered vegetable drugs with particular reference to development of a system of identification ,J Am pharm. Sci. 1967.38,324.

[4] Anonymous, British pharmacopoeia, general medical council, pharmaceutical press 17 , Bloomsbury square London 1968, p.1209

Citation: Bello Hassan Onimisi, "Physicochemical Studies of Calleandria Portoricensis Spp", International Journal of Research Studies in Medical and Health Sciences. 2021; 6(4): 9-10. DOI: https:// doi.org/10.22259/ijrsmhs.0604003

Copyright: (C) 2021 Bello Hassan Onimisi, This is an open-access article distributed under the terms of the Creative Commons Attribution License, which permits unrestricted use, distribution, and reproduction in any medium, provided the original author and source are credited. 